RESENHA

\title{
A criança, a matemática e a realidade: problemas do ensino da matemática na escola elementar
}

\author{
Mônica de Oliveira Pinheiro da Silval (D)
}

\begin{abstract}
VERGNAUD, G. ${ }^{1}$ A criança, a matemática e a realidade: problemas do ensino da matemática na escola elementar. Tradução Maria Lucia Faria Moro; revisão técnica Maria Tereza Carneiro Soares. Curitiba: Editora da UFPR, 2009. 322p.
\end{abstract}

Gérard Vergnaud nos apresenta a obra $A$ criança, a matemática e a realidade: problemas do ensino da matemática na escola elementar, publicada pela Editora da Universidade Federal do Paraná (UFPR). Atualmente Vergnaud exerce orientação de investigação e docência na área de competências cognitivas em situação escolar e do trabalho no Laboratório Paragraphe da Universidade de Paris. Foi o criador de uma teoria: a teoria dos campos conceituais (TCC). Para esse autor, campo conceitual compõe um conjunto informal e heterogêneo de problemas, situações, conceitos, relações, estruturas, conteúdos e mecanismos de pensar, que se conectam e se comunicam durante o processo de aquisição de conceitos de maneira geral. Seus estudos versam sobre conceitos matemáticos com suas estruturas aditivas e multiplicativas, nas quais se baseiam teorias e temas diversificados dessa área. É a partir do domínio dessas estruturas que outros conceitos serão compreendidos, tais como: estruturas de grupo, a teoria dos espaços vetoriais, funções lineares e não lineares, entre outros.

A obra em resenha teve como título original Lefant, la mathematique et la réalité, com sua primeira edição em francês publicada há mais de vinte e cinco anos.

\footnotetext{
'Universidade de Sorocaba, Sorocaba, SP, Brasil.

${ }^{1}$ Nascido em 1933, Gérard Vergnaud é doutor em psicologia pela Universidade de Paris Sorbonne, tendo como orientador de sua tese Jean Piaget. Em Sorbonne construiu sua carreira consolidada como professor, sendo durante vários anos diretor de pesquisa do Centre National de Rechesches Scientifiques (CNRS), na área de psicologia do desenvolvimento cognitivo.
} 
Foi lançada no Brasil em português em 2009, mas também conta com traduções em italiano, espanhol e russo. Ela é composta de doze capítulos, nos quais Vergnaud aprofunda a TCC de forma didática em relação à aquisição dos conceitos matemáticos, com exemplos e definições.

O livro inicia pela definição de relação, apresentando e diferenciando as relações binárias, ternárias e quaternárias. Além da definição, são enunciadas as suas propriedades, com variados exemplos. Especialmente para as relações ternárias e quaternárias, é apresentada a noção de transformação, enfatizando que essa noção esclarece inúmeras noções matemáticas e facilita a análise de numerosos problemas. Para tanto, nos quatro primeiros capítulos estão abordadas as diferentes relações (binárias, ternárias, quaternárias), sendo introduzido o termo "cálculo relacional", finalizando com as relações e as tarefas escolares. A parte inicial encerra-se com a noção de aplicação e sua importância para o estudo de funções para casos não numéricos, fechando com o cálculo relacional dentro da compreensão dessas relações.

Estando definidas as relações, o autor situa a TCC para as relações e as tarefas escolares, enfatizando a possibilidade de ligar os conceitos definidos anteriormente com os temas tratados desde as séries iniciais. Para tanto, Vergnaud analisa questões que julga fundamentais para que se trabalhem as relações, que são: o espaço, as propriedades dos objetos, relações de parentesco, números e a variedade de domínios utilizáveis.

No quinto capítulo são abordadas as classificações e as operações, e no sexto e sétimo são tratadas as medidas, com alguns problemas práticos e também teóricos. A medida é vista de maneira que amplia os problemas de contagem: comprimento, áreas, volumes, peso. No contexto de comparar medidas, Vergnaud as coloca em relação biunívoca entre as grandezas, a fim de decidir a maior ou a menor. Nessa visão para melhor se fazer a comparação, introduz o objeto intermediário, que é do mesmo modo uma grandeza. Também encontramos níveis de diferenciação da matemática, como a da atividade de composição de objetos complementares da atividade de comparação e classificação.

O tratamento em relação à numeração é visto no oitavo capítulo, no qual número é definido, como também o sistema de numeração sendo considerado um suporte para a aquisição do seu conceito. Nessa parte da obra o conceito de número é apoiado em outras noções (mais aprofundadas), tais como a de aplicação, de correspondência biunívoca, de relação de equivalência, de relação de ordem. É salientada ao leitor a importância dada à fala numérica, quando a criança enuncia uma sequência numérica, passando pelo nível da recitação até o nível da contagem (quando ela é capaz de estabelecer uma correspondência entre o conjunto de objetos de um lado e a sequência falada de outro).

No nono capítulo são apresentados os problemas do tipo aditivo, com abordagem dos números naturais e relativos, inteiros e decimais, caracterizando as seis grandes categorias de relações aditivas. Para as primeiras aquisições das estruturas numéricas, o autor estipula quatro planos: dos objetos, do conjunto dos objetos, dos cardinais e de conjuntos e, por último, o plano das representações escritas desse número. Para a aprendizagem da numeração, o autor exemplifica a variedade de 
situações que podem ser trabalhadas explorando-se, de maneira simples, o plano do homomorfismo (uma aplicação que conserva as estruturas de um grupo das estruturas). São esclarecidos de forma ampla os problemas do tipo aditivo, relações aditivas e as transformações advindas dessas relações, com referência aos números naturais, relativos e decimais. $\mathrm{O}$ autor faz uma análise detalhada dos problemas e dificuldades de se operar não só em virtude das diferentes categorias das relações numéricas, mas também em razão das diferentes classes de problemas que podem ser formulados para cada categoria.

No décimo capítulo é trazida a noção de grupo, resultante das transformações aditivas e multiplicativas, satisfazendo condições específicas. Um grupo contempla as seguintes propriedades: comutativa, associativa, elemento neutro e inverso. A partir daí são apresentados exemplos de grupo e demonstrações de operações que os caracterizam, como também a exploração da relação quaternária contida nos problemas do tipo multiplicativo.

No décimo primeiro capítulo são novamente revistas as relações multiplicativas, incluindo aí análises verticais (escalar) e horizontais (função), bem como o produto de medidas. No décimo segundo capítulo o autor apresenta situações e exemplos de representação e de solução de problemas aritméticos complexos, nos quais várias relações e diferentes questões possíveis são apresentadas. Nas conclusões, Vergnaud retoma as noções de homomorfismo (mesma forma) relacionadas com os problemas de matemática, esclarecendo que tais noções permitem colocar com clareza o problema do ensino da matemática, categorizando diferentes hierarquias.

O tempo de lançamento da obra não elimina nem diminui sua originalidade, importância e seu caráter atual ao abordar o cálculo com suas estruturas aditivas e multiplicativas, que vão muito além das quatro operações.

O livro é voltado para professores que ensinam matemática, desde as séries iniciais até o ensino superior, com o intuito de analisar a formação dos conceitos e diferentes domínios do pensamento racional, com formação de esquemas como uma das maneiras de organização do pensamento e de atividades que expressam o conhecimento em situação. De maneira ousada, a obra adentra nos problemas ditos fundamentais no ensino da matemática, como as quatro operações. A variedade e a riqueza de exemplos permitem ao leitor emaranhar-se pelos conceitos fundamentais da matemática pela ótica das análises mais aprofundadas, com a visão de n-relações que entrelaçam e classificam os números e suas operações. Importar observar que para cada assunto há a recomendação da série escolar em que poderá ser trabalhado.

Recomenda-se também a utilização dessa obra em cursos de licenciatura em matemática, bem como nos cursos de pedagogia. Verifica-se de forma abrangente como a matemática é tratada, com análises que aprofundam o suficiente suas questões mais importantes e estruturais: o campo aditivo e o multiplicativo. Ressalta-se o aspecto psicológico que perpassa todo o livro, pois a TCC valeu-se da psicologia da cognição para tal especificidade. Não apenas com exemplos e definições matemáticas, mas também temas a serem ensinados de forma completa, conhecendo-se o modo de aprender, para então investir na maneira de ensinar. 


\section{REFERÊECIA}

VERGNAUD, G. A criança, a matemática e a realidade: problemas do ensino da matemática na escola elementar. Tradução Maria Lucia Faria Moro; revisão técnica Maria Tereza Carneiro Soares. Curitiba: Editora da UFPR, 2009.

\section{SOBRE A AUTORA}

Mônica de Oliveira Pinheiro da Silva é doutoranda em educação pela Universidade de Sorocaba (UNISO). Professora na Faculdade de Tecnologia de Sorocaba (FATEC-SO).

E-mail:profmonica@gmail.com

Recebido em 10 de outubro de 2018

Aprovado em 13 de março de 2019 